through wk 52. Pharmacodynamic responses (neutrophil and high-sensitivity CRP levels) plateaued at the $100 \mathrm{mg}$ dose and data were similar at $200 \mathrm{mg}$. The low immunogenicity to lutikizumab did not meaningfully affect outcomes.

Conclusions: Lutikizumab was generally well tolerated and met the primary endpoint of reduction in WOMAC pain at wk 16 compared with placebo at a dose of $100 \mathrm{mg}$, but not at $25 \mathrm{mg}$ or $200 \mathrm{mg}$; cartilage thickness, synovitis, and other structural endpoints were similar between lutikizumab and PBO.

Acknowledgements: AbbVie funded the study (NCT02087904), contributed to its design and participated in data collection, analysis and interpretation of the data, and in writing, review, and approval of the publication. Medical writing (funded by AbbVie): Richard M. Edwards, PhD, and Michael J. Theisen, PhD of CPS.

Disclosure of Interest: R. Fleischmann Grant/research support from: AbbVie, Consultant for: AbbVie, H. Bliddal Consultant for: AbbVie Inc., Roche, Pfizer, Lilly, F. Blanco Consultant for: AbbVie Inc., Pfizer, UCB, Bristol, Roche, Bioiberica, Sanofi, Grünenthal, GlaxoSmithKline, Lilly, Janssen, Regeneron, TRB Chemedica (DISSCO), T. Schnitzer Grant/research support from: AbbVie, Consultant for: AbbVie, C. Peterfy Shareholder of: Spire Sciences, Inc. (which provides imaging services for clinical trials to multiple pharmaceutical companies), Employee of: Spire Sciences, Inc. (which provides imaging services for clinical trials to multiple pharmaceutical companies), S. Chen Shareholder of: AbbVie, Employee of: AbbVie, L. Wang Shareholder of: AbbVie, Employee of: AbbVie, P. Conaghan Consultant for: AbbVie Inc., Medivir, Merck Serono, Novartis, Pfizer, Speakers bureau: AbbVie, F. Berenbaum Consultant for: AbbVie, Pfizer, Regeneron, J.-P. Pelletier Consultant for: AbbVie, J. Martel-Pelletier Consultant for: AbbVie, O. Vaeterlein Employee of: Bioclinica, W. Liu Shareholder of: AbbVie, Employee of: AbbVie, G. Levy Shareholder of: AbbVie, Employee of: AbbVie, L. Zhang Shareholder of: AbbVie, Employee of: AbbVie, J. Medema Shareholder of: AbbVie, Employee of: AbbVie, M. Levesque Shareholder of: AbbVie, Employee of: AbbVie DOI: 10.1136/annrheumdis-2018-eular.2727

\section{SAT0576 BIOMARKERS PREDICTIVE OF PAIN IMPROVEMENT IN KNEE OSTEOARTHRITIS SUBJECTS TREATED WITH THE ANTI-IL-1 ALPHA/BETA DUAL VARIABLE DOMAIN IMMUNOGLOBULIN LUTIKIZUMAB (ABT-981)}

S. Feng ${ }^{1}$, S. Chen ${ }^{1}$, L. Wang ${ }^{1}$, C. Peterfy ${ }^{2}$, V. Kraus ${ }^{3}$, R. Kamath ${ }^{1}$, L. Zhang ${ }^{1}$, Y. Luo ${ }^{1}$, L. Cui ${ }^{1}$, J. Medema ${ }^{1}$, M. Levesque ${ }^{1} .{ }^{1}$ AbbVie Inc., North Chicago; ${ }^{2}$ Spire Sciences, Inc., Boca Raton; ${ }^{3}$ Duke University School of Medicine, Durham, USA

Background: Development of disease-modifying drugs for OA has been challenging, partly due to lack of predictive biomarkers.

Objectives: Our primary objective was to identify baseline $(B L)$ biomarkers predicting greater treatment effects on WOMAC pain among knee OA subjects in the lutikizumab (formerly ABT-981) ILLUSTRATE-K trial (NCT02087904).

Methods: Subjects $(n=347)$ with Kellgren-Lawrence $(K L)$ grade $2-3$ knee OA, synovitis on MRI or ultrasound, and knee pain score 4-8 (range, 0-10) were randomised to placebo (PBO) or lutikizumab 25, 100, or 200 mg subcutaneously every $2 \mathrm{wk}$ for $50 \mathrm{wk}$. The primary endpoints were change from BL (CFB) in WOMAC pain at wk 16 and CFB in MRI synovitis at wk 26. Demographics, patient-reported outcomes (WOMAC, ICOAP, global assessment [PGA]), x-ray joint space width, and Whole Organ MRI Score (WORMS) were determined at BL. The Patient Rule Induction Method, Sequential Batting, and the Adaptive Index Model were used to identify $\mathrm{BL}$ predictive biomarkers and $\mathrm{OA}$ subsets with greater lutikizumab treatment effects. Continuous efficacy endpoints were assessed using ANCOVA with treatment, age group, and $\mathrm{KL}$ grade as main factors and $\mathrm{BL}$ measurements as covariates with LOCF imputation for WOMAC pain.

Results: WORMS Global Total Osteophyte Score (GTOS), which semi-quantitatively summates osteophyte severity from 14 regions of the knee, identified a subset of subjects with a greater lutikizumab treatment effect vs PBO; the optimal GTOS cutoff for discriminating treatment effects was 14 (figure 1). Among subjects with a GTOS $\geq 14$, the PBO WOMAC pain response was markedly reduced and only marginally improved for ABT-981. At wk 16, among subjects with GTOS $\geq 14$, the standardised mean difference $(95 \% \mathrm{Cl})$ of WOMAC pain for the lutikizumab $100 \mathrm{mg}$ dose group vs PBO was -0.62 ( -0.16 to -1.09$)$ vs -0.30 (0 to -0.61 ) for all subjects. Compared with the total study population, the $41 \%$ of subjects with GTOS $\geq 14$ not only had a greater ABT-981 treatment effect vs PBO on WOMAC pain, but also other measures of OA symptoms. BL systemic markers of synovitis (serum C1M and C3M) and potential markers of macrophage activation by IL-1 (serum alkaline phosphatase) were positively associated with greater lutikizumab treatment effects vs PBO but to a lesser extent than GTOS. Other data supported the robustness of the GTOS predictive marker because 1) a priori, $\mathrm{KL}$ grade was used to stratify subjects, 2) subject characteristics were balanced and 3) osteophyte formation is directly linked with synovial macrophage numbers in humans and OA synovial macrophages are the predominant source of IL-1, which is an important mediator of pain.

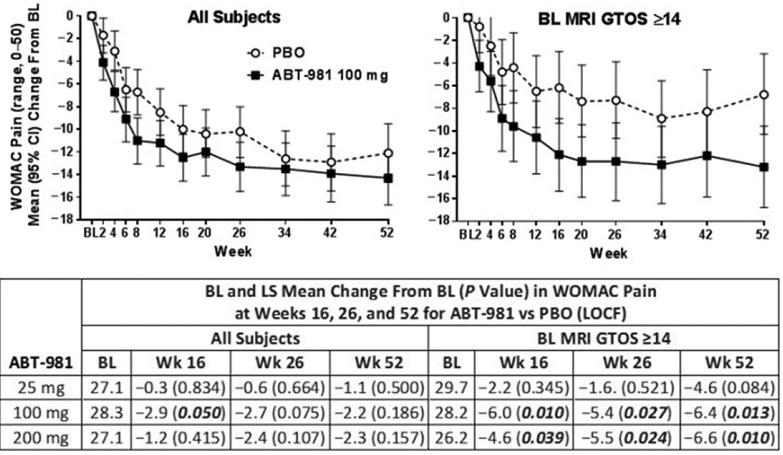

Abstract SAT0576 - Figure 1

Conclusions: The GTOS biomarker predicted improvement of knee OA pain and other symptoms with lutikizumab treatment. We hypothesise that subjects with more severe osteophytes may have had more inflammation-dependent pain that was less responsive to $\mathrm{PBO}$, suggesting that IL-1 inhibitors should be studied further as a treatment for knee OA symptoms in this subset of patients.

Acknowledgements: AbbVie: study sponsor, contributed to design, data collection, analysis, interpretation; and writing, reviewing, approval of final version. AbbVie Funded Medical writing: RM Edwards, MJ Theisen of CPS.

Disclosure of Interest: S. Feng Shareholder of: AbbVie, Employee of: AbbVie, S. Chen Shareholder of: AbbVie, Employee of: AbbVie, L. Wang Shareholder of AbbVie, Employee of: AbbVie, C. Peterfy Shareholder of: Spire Sciences, Inc. (which provides imaging services for clinical trials to multiple pharmaceutical com panies), Employee of: Spire Sciences, Inc. (which provides imaging services for clinical trials to multiple pharmaceutical companies), V. Kraus Consultant for: AbbVie, R. Kamath Shareholder of: AbbVie, Employee of: AbbVie, L. Zhang Share holder of: AbbVie, Employee of: AbbVie, Y. Luo: None declared, L. Cui Shareholder of: AbbVie, Employee of: AbbVie, J. Medema Shareholder of: AbbVie, Employee of: AbbVie, M. Levesque Shareholder of: AbbVie, Employee of: AbbVie

DOI: 10.1136/annrheumdis-2018-eular.2730

\section{SAT0577 EVALATUION OF SARCOPENIA MULTIDIMENSIONALLY IN PATIENTS WITH KNEE OSTEOARTHRITIS}

S. Gümrük Aslan, M. Saraçoğlu, H. Genç, B. D.Çakıt, B. Nacır. University of Health Science, Ankara Training and Research Hospital, Physical Medicine and Rehabilitation Clinic, ANKARA, Turkey

Background: Osteoarthritis $(\mathrm{OA})$ is a noninflammatory chronic degenerative dis ease.The rate of development of sarcopenia has been increased in patients with OA.

Objectives: In this study,we evaluated the presence of sarcopenia multidimensionally in patients with knee osteoarthritis $(\mathrm{OA})$ using clinical,ultrasonographic and biochemical parameters, and in this respect, it was aimed to investigate the relation between $\mathrm{OA}$ and sarcopenia and to identify the most practical,easily accessible and inexpensive method for investigating sarcopenia.

Methods: 102 patients with clinical and radiological diagnosis of knee osteoarthritis and 33 healthy control subjects were included in the study.A total of 135 subjects were evaluated by the European Working Group on Sarcopenia in Older People (EWGSOP) for the diagnosis of sarcopenia.The first group consists of (OA) patients with sarcopenia, the second group consist of OA patients without sarcopenia and the third group is controls subjects.Dual-X-ray absorptiometry (DEXA) is used to measure Body composition parameters and muscle mass measurements, isometric muscle strength evaluations, hand grip strength and walking speeds for diagnosis of sarcopenia. Short form -36 (SF-36) The Nutritional Assesment-short form (MNA), the Western Ontario and McMaster Universities Osteoarthritis Index (WOMAC), the International Physical Assessment Questionnaire Short Form (IPAQ-SF) and the Centre for Epidemiologic Studies Depression Scale (CES-D scale) were administered to every patients.

Results: The mean age of the group with sarcopenia was statistically higher than the other two groups $(p<0.001)$. The weight, body mass index $(B M I)$, waist circum ference, upper mid-arm circumference, thigh and leg circumference of osteoarthritis (OA) patients with sarcopenia were statistically lower than those of nonsarcopenic and control group $(p<0.01 p<0.001)$. Body composition parameters results showed that sarcopenic patients had statistically lower values as fat mass, lean body mass and Skeletal Muscle Index $(p<0.001, p=0.001, p<0.001$, respectively) than those of non-sarcopenic and control group.lt was determined that body composition values measured with DEXA, ultrasonogrphic measures, 